\title{
La naturaleza y la violencia en La perra de Pilar Quintana
}

\section{Nature and Violence}

\section{in Pilar Quintana's La perra}

\section{Greg Przybyla ${ }^{1}$}

University at Buffalo, USA.

DOI: http://dx.doi.org/10.15648/c1.30.2019.6

\section{(c) (1) (2)}

1 Doctorado en Literatura Hispánica (Ph.D.), University at Buffalo, SUNY. Profesor Asistente de Español, Eckerd College, St. Petersburg, Florida, Estados Unidos. Correo electrónico: przybyg@eckerd.edu 


\section{Resumen}

Este trabajo indaga el papel de la naturaleza dentro de la novela La perra (2018) de la escritora colombiana Pilar Quintana. En este trabajo, se partirá de la importancia de la dicotomía civilización/barbarie propuesta por Domingo Sarmiento en el siglo XIX para revelar la manera en que la naturaleza servía como trasfondo inerte que el ser humano explotaba en su misión neocolonizadora. En La perra, Quintana interrumpe este discurso y desromantiza la selva mediante la ubiquidad de la violencia y la muerte. Así, se reflexiona sobre el poder inquebrantable de la naturaleza en una región históricamente marginada de América Latina.

Palabras clave: novela, Pilar Quintana, dicotomía, discurso.

\begin{abstract}
This work investigates the role that nature plays in Pilar Quintana's 2018 novel La perra. The following will start by briefly thinking through Domingo Sarmiento's civilization/barbarism dichotomy as a way of revealing how during the $19^{\text {th }}$ century nature's primary purpose was to serve as a passive backdrop to be exploited by humans and their neo-colonizing mission. In La perra, Quintana interrupts this discourse and de-romanticizes the jungle by way of the ubiquity of violence and death. In doing so, one is able to reflect upon the supreme force of nature in a historically marginalized and underrepresented region of Latin America.
\end{abstract}

Keywords: novel, Pilar Quintana, dichotomy, speech. 


\section{"De eso se trata: de ser o no ser salvaje". \\ Domingo Faustino Sarmiento, Facundo}

Resulta fácil encontrar lazos entre la literatura latinoamericana y la naturaleza; desde la conquista hasta la época contemporánea los casos abundan con uno de los más canónicos siendo Facundo: civilización y barbarie (1845), escrito por Domingo Faustino Sarmiento. Este ha sido estudiado e interpretado de muchas maneras, entre estas se destaca la oposición entre la civilización y la barbarie, o el enfrentamiento entre la vida culta de las ciudades y la vida "atrasada" del campo argentino. A la vez es factible considerar el ensayo -especialmente su tratado sobre las redes fluviales- como los principios del mejoramiento de la topografía de la nación con tal de encaminar al país hacia la comercialización, la industrialización y por supuesto, la modernización. Estas transformaciones del paisaje vislumbran algunos de los primeros pasos de la explotación ecológica del país y por tanto la relegación de la naturaleza a un lugar secundario, dominada por las fuerzas neocolonizadoras.

Más allá de estas interpretaciones, Sarmiento entiende en la naturaleza y el campo uno de los principales culpables del retroceso argentino, manifestando su postura en el siguiente:

Ahora llega desde los Andes hasta el mar: la barbarie y la violencia bajaron a Buenos Aires, más allá del nivel de las provincias. No hay que quejarse de Buenos Aires, que es grande y lo será más, porque así le cupo en suerte. Debiéramos quejarnos, antes, de la Providencia, y pedirle que rectifique la configuración de la tierra...Quejémonos de la ignorancia de este poder brutal, que esteriliza para sí y para las provincias los dones que natura prodigó al pueblo que extravía. Buenos Aires, en lugar de mandar ahora luces, riqueza y prosperidad al interior, mándale solo cadenas, hordas exterminadoras y tiranuelos subalternos. (p. 20)

Como parte del enfrentamiento entre la civilización y la barbarie, hay que subrayar lo que según el argentino es el poder que entraña esta última y los estragos que ha causado dentro del continente. No obstante, este poder no solo se limita a la nación Argentina y sus culturas, sino que ha repercutido dentro de las culturas latinoamericanas durante los siglos XIX y XX, continuando hasta la actualidad. Como resultado por perjudicar una vasta nación y una multitud de identidades reduciéndolas a una pequeña parte del todo, estos mecanismos destacan la ciudad 
y la cultura occidental como el gran y único telos al que toda sociedad latinoamericana debe aspirar. Sarmiento señala que "los progresos de civilización se acumulan en Buenos Aires solo: la pampa es un malísimo conductor para llevarla y distribuirla en las provincias" (p. 20-21). Así, de un plumazo ningunea por completo al campo al mismo tiempo que atribuye a la ciudad -y solo a la ciudad -todas las características que ayudarían a que la nación Argentina y las demás naciones latinoamericanas se codearan con las más poderosas del Occidente.

En cambio, el campo y la barbarie se ubican al otro extremo. Encarnado en la figura de Juan Manuel de Rosas, el campo es todo lo que la sociedad cosmopolita no es y no quiere ser; es el caudillismo, lo inculto y lo salvaje. Según Sarmiento, estos entes representan aún más, lo inmanente, o la paralización de la búsqueda de la libertad. Lejos de las huellas de la civilización y el liberalismo, en el campo, es la naturaleza la que toca y se inserta en todos los aspectos de la vida. Por eso, durante el siglo XIX la naturaleza se asocia con una falta de agencia donde las acciones de cada uno están regidas por algún órgano rector externo al sujeto que dicte las conexiones que uno debe hacer en el mundo y cómo se debe sentir e interpretar esas conexiones.

En lo concerniente al presente estudio, la figura en cuestión y la que rige es una que muchas veces se da por sentado como inerte: la naturaleza misma. Es la naturaleza la que impone y avasalla; frente a ella el sujeto siente impotencia y frustración, lo cual muchas veces se manifiesta en actitudes de conformismo y resignación en los sujetos. La naturaleza actúa como meta-narrativa que desafía y hasta reemplaza a las demás narrativas. Esto era uno de los mayores miedos de Sarmiento y por el cual era su visión convertir a la nación en una balanza que siempre se inclina a favor de una civilización que devoraba - a veces literalmente- a la barbarie.

En La perra (2017) de Pilar Quintana, los lectores se transforman en testigos de la misma oposición entre civilización y barbarie que Sarmiento había ideado casi dos siglos atrás. Por lo tanto, este artículo parte de la inexorabilidad de la filosofía sarmientina en la literatura latinoamericana y lo enquistada que está en la producción cultural del continente. Luego, en una manera similar a algunas obras del género latinoamericano de novela de la selva como los Cuentos de amor, de locura y de muerte (1917) del uruguayo-argentino Horacio Quiroga y La vorágine (1924) del colombiano José Eustasio Rivera, donde en la estimación de Ana María Mutis (2014) "la Amazonia emula un descenso al infierno y la selva es presentada como una cárcel vegetal, una espacio maléfico que atrapa y devora inmisericordemente a los protagonistas" (p. 186), en La perra se enfrenta a una natu- 
raleza selvática protagónica cuya influencia en la formación de cada personaje es insoslayable. La novela de Quintana hace replantear la relación entre naturaleza y ser humano que postula Christopher Mannes (1996) cuando escribe que "[n] ature is silent in our culture (and in literate societies generally) in the sense that the status of being a speaking subject is jealously guarded as an exclusively human prerogative" (p. 15). Aquí la selva hablará y se dejará conocer íntimamente desde el suelo, aunque a veces no le preste atención. Esta perspectiva contrasta con la neocolonizadora de la panorámica; sus particularidades, sus habitantes no humanos, su topografía, todos salen a la luz en la novela de Quintana. Aquí, el entorno natural de la selva colombiana es un espacio oscuro que emerge como figura innegable en la vida de los protagonistas humanos, y que llega a significar nada menos que la violencia y la muerte.

En La perra, los lectores se adentran en un mundo atrasado en el cual toda institución establecida por los seres humanos se derrumba ante el peso de la naturaleza; es este el mundo cuyas fuerzas Sarmiento temía y por las cuales pregonaba los avances de la civilización y la erradicación de la barbarie. Aquí en el aislamiento de las selvas de la costa pacífica colombiana, toda iniciativa de ejercer agencia y toda capacidad de crear nuevas conexiones con el mundo se desvanecen, rindiéndose ante el poder del medioambiente y anclándose en una identidad estática y sin esperanza de progresar.

Dentro de este contexto, en la novela de Quintana se perciben atisbos de la ecocrítica y del ecofeminismo. En otras palabras, la naturaleza romperá con el molde hegemónico del siglo XIX y XX cuando su "función primordial era ser el trasfondo para la afirmación del yo masculino" (Kearns, 2006, p. 112). En el presente la naturaleza se convierte en un ente con que no solo comparte el mundo el ser humano, sino que trastoca la narrativa sarmientina al mismo tiempo que desprivilegia al sujeto humano. La relación anterior de explotación y aprovechamiento llevado a cabo por el hombre da un giro considerable hacia una basada en la violencia y la imposición por el medioambiente. Este giro coincide con la reflexión de Laura Barbas-Rhoden (2012) y sirve para "underline the absurdity of modernizing plans" (p. 86), a la vez que descubre las falencias de un reduccionismo cultural que favorece al hombre como único agente activo. En La perra se hace evidente la interacción entre naturaleza y ser humano -es imposible evitarla. Por eso, el enfoque del presente es refundir esta dicotomía e interrogar el papel inexorable de la naturaleza y la manera en que, mediante la violencia, desdibuja la impresión de las huellas humanas en la tierra. Asimismo, se evoca lo que la filósofa ecofeminista Val Plumwood (2006) describe como "a dialogical kind of story that sees the land as a field of (product, outcome, child/offspring of) 
multiple interacting and collaborating agencies which can include humans but is never exhausted by them" (p. 125). En La perra, la naturaleza llegará a ser una agente activa, invirtiendo la dicotomía de Sarmiento y desplazando al hombre a un lugar secundario.

Pilar Quintana nació en Calí, Colombia en 1972. Además de La perra, novela por la cual ganó el Premio Biblioteca de Narrativa Colombiana 2018, ella ha escrito cuatro novelas y varios cuentos, por los cuales en 2007 fue elegida como uno de los escritores más prometedores menores de treinta y nueve años en América Latina. Aunque los temas de su trabajo varían, tres hilos que subyacen en casi toda su obra, y que ella manifiesta sin tapujos, son la violencia, el sexo y la pugna cotidiana de la mujer colombiana dentro de la sociedad. Además, la narrativa de Quintana se destaca por su calidad de sencillo; Quintana escribe de una manera clara y sin rodeos, lo cual hace más asequible su obra. Si bien algunos críticos afirman que su trabajo se basa en hechos biográficos -especialmente La perra, novela que la hizo saltar a la fama- más que nada sus obras se centran en las experiencias con que los lectores se pueden identificar en la vida.

Es importante señalar que La perra se aparta de los lugares comunes de las tres novelas anteriores de Quintana, que tenían lugar en espacios urbanos y que abarcaban cuestiones preponderantes de este espacio. En el caso de La perra, Quintana pone bajo la lupa una Colombia muchas veces olvidada y arroja luz sobre un espacio y una cultura que antes quedaban relegados a un segundo plano. De una manera parecida a la que Lesley Wylie (2006) indaga a los autores del género de novela de la selva del siglo XX, Quintana sitúa La perra en esta región geográfica no como "a yielding to colonial tropes, but a means of asserting their unknowability, and their location outside of European epistemology" (p. 733). A no dudar que el interés de Wylie por las obras de escritores como José Eustasio Rivera y Alejo Carpentier, se deja guiar por las circunstancias históricas y las influencias socioculturales europeas de la primera mitad del siglo XX cuando la hegemonía estadounidense aún no se había expandido a los países de América Latina con el ímpetu que tendría después de la Segunda Guerra Mundial. Mientras tanto, el interés de Quintana casi cien años después sirve más como discurso contrahegemónico que hace frente a un neo-imperialismo rampante encabezado por los Estados Unidos y su afán capitalista, y así introduce lo que se desconoce y lo que queda marginado por la epistemología dominante de la mitad del siglo XX hasta la actualidad.

La trama de la novela sigue la vida de Damaris, una mujer negra que vive en la costa pacífica colombiana en un pueblo rodeado de la presencia lúgubre de la 
selva tropical. Damaris es una mujer que ronda los cuarenta años y que vive en un pueblo en las afueras de la ciudad portuaria de Buenaventura, donde la vida se destaca más que nada por la falta de comunicación con el mundo exterior, la soledad individual y el continuo hostigamiento del mundo natural. Ella se encuentra en un matrimonio infeliz con su esposo Rogelio con quien no ha podido -y hasta ha perdido la ilusión de- tener hijos. Debido a esta ausencia y esta maternidad frustrada, ella adopta a una perra con la esperanza de llenar el vacío que le ha dejado el hecho de no poder tener una familia como una mujer "normal," según opera el discurso patriarcal de la región. De esta forma, la novela traza los (dis) gustos de Damaris no solo en su relación con la perra -Chirli- sino en las que ella tiene con otros personajes y hasta con el medioambiente. Es una historia en la cual los protagonistas están predeterminados a una vida mezquina y por lo cual se puede comprender a Damaris como anti-heroína, rol que Charlotte Rogers (2016) define como uno en el cual los protagonistas "do not set out on an adventure, overcome obstacles or vanquish foes, nor do they return home changed by their time in the jungle" (p. 1051). A lo largo de la novela Damaris se distancia de los discursos de poder que marcan la civilización y experimenta un descenso paulatino que la acerca a la naturaleza que al final de todo la convertirá irremediablemente en una extensión de la misma selva que ella habita.

"Esta mañana la encontré ahí, patas arriba" (p. 9); así abre Quintana en media res su novela, en una escena moribunda donde junto con doña Elodia, Damaris contempla el cadáver de una perra muerta en las orillas del Pacífico. La novela empieza con esta escena gráfica y así da a la luz el concepto barroco de la ubicuidad de la muerte dentro de este ambiente "foráneo" y hostil. Es dentro de este panorama -y desde ese momento en la novela- que la naturaleza de pronto toma un protagonismo crítico en la vida de Damaris y cuya hegemonía sobre ella influirá determinadamente.

Para esclarecer el alcance de la naturaleza y su papel dentro de la obra, primero se trazará una descripción física de ella, ya que la inhospitalidad del suelo y del clima donde "los troncos podridos que todavía quedaban en pie parecían las lápidas descuidadas de un cementerio" (Quintana, p. 20) se deja entreverar la muerte aún más que la escena que da comienzo a la novela. Más allá de ilustrar una imagen impregnada por la muerte, esto representa un memento mori que avisa que la mortalidad acecha y que puede llegar cuando menos la espera uno. Si uno sopesa lo que asevera María Ospina (2014) como "la reinscripción de una naturaleza alejada de la cultura [que] sirve para situar a quienes la habitan - guerrilleros, campesinos, indígenas, - fuera de los parámetros nítidos de la nación, impidiendo considerarlos como grupos que, de una u otra manera, también la conforman" ( $p$. 
257), los troncos podridos sirven como una manera de agrandar aún más la grieta entre ciudad y barbarie mediante la omnipresencia de la muerte. Aquí, en medio de la selva y marginada de los centros de salud y los avances en la medicina que existen en las conglomeraciones urbanas, la gente vive como rehenes de la naturaleza, o como Quintana describe, "muerta de susto por las explosiones de los rayos y la furia del vendaval...diminuta, más pequeña y menos importante en el mundo que un grano de la arena del mar" (p. 17).

No obstante, lo que contribuye al poder de la naturaleza no es solo lo que infunde la selva y el miedo que provoca sino lo que esconde en sus entrañas. Quintana ilumina esta noción durante una escena clave en la cual Chirli, la perra que adopta Damaris, escapa y se pierde por la selva. Inmediatamente después de darse cuenta de la ausencia de la perra, Damaris va en busca de ella. Sin embargo, antes de adentrarse en la selva ella se detiene a contemplar momentáneamente todo lo que le espera más allá del umbral de la selva, un límite que marca los principios de lo que Quintana describe como una "bestia que acabara de tragarse a su presa" (p. 50). Es dentro de esta "bestia" que Damaris corre el peligro de cruzarse con "la oscuridad, las equis, las fieras, los muertos, el finado Nicolasito, el finado Josué y el finado señor Gene, los espantos de los que había oído hablar cuando niña" (Quintana, p. 50). De este modo, la selva es comprendida como un monstruo recalcitrante e imprevisible. Es una fuerza que amenaza a cada paso a la cultura occidental, noción que queda encarnada en la repetida "invasión de hormigas, miles y miles avanzando por entre la selva como un ejército...que salían de sus nidos debajo de la tierra y arrasaban con todos los bichos vivos o muertos que se encontraban" (Quintana, p. 55).

Además, la selva resulta ser un poder determinante en el imaginario de los sujetos que viven dentro de ella. Su influencia se extiende más allá de la biodiversidad e incorpora los (des)encuentros de cada individuo y sus interacciones con ella. En el caso de Damaris, estos son representados por la muerte de algunas personas cercanas a ella más las historias de la selva que ella escuchaba cuando era niña. Como se observará más adelante, el imaginario de Damaris contrastará fuertemente con el de su amigo Nicolasito quien solo visita la selva para pasar sus vacaciones y cuya visión romántica chocará fuertemente con la realidad. Así, la selva no es solo un ente que se manifieste físicamente ante Damaris y los demás personajes sino se compone tanto de los objetos que viven en ella como de las imágenes y los recuerdos que perduran en la memoria y de los cuales no se puede escapar ni reescribir. En Damaris, estas costumbres, estas historias y esta cultura han sido reafirmadas tanto que se han convertido en una esencia inmutable. 
Por otra parte, se evidencia una idea que Sofía Kearns sostiene en su análisis del papel de la naturaleza en la literatura colombiana contemporánea: "se desromantiza aquí a la naturaleza, siendo ya no refugio o santuario para los humanos" (p. 114). La naturaleza deja de existir solo para el aprovechamiento del hombre y deja de representar un paraíso para la contemplación humana como si fuera alguna utopía como lo era Walden Pond para Henry David Thoreau ${ }^{2}$ en el siglo XIX o para otros escritores (latino)americanos románticos. Esas visiones de la naturaleza que se habían naturalizado en el imaginario cultural a lo largo del siglo diecinueve pronto se fragmentan, dejando un hueco para otras interpretaciones que desafían a las anteriores. En lo tocante al presente, esta desromantización se entiende como cierta resistencia de la selva hacia la intrusión de la sociedad. Es decir, que la naturaleza se desromantiza mediante la violencia y la opresión. Donde el Romanticismo recalcaba la voz poética del "yo" subjetivo frente al mundo natural y subrayaba una conexión casi espiritual junto con una "tendency to idealize and anthropomorphize nature...such that the land ambivalently embodies the protagonists' attitudes and emotions" (DeVries, p. 538), en La perra se observa un poder inquebrantable de la naturaleza que desestabiliza la noción de una realidad histórica impuesta desde afuera por el hombre y sus discursos de poder. La naturaleza es un poder que abate y somete constantemente sin importar los discursos del hombre; es uno que según Quintana "parecía aplastar a la tierra" (p. 68); es una autoridad que desdibuja a esos topos comunes y totalizadores, y limita, como se verá más adelante, cualquier manifestación de ese "yo" subjetivo.

Por otro lado, la naturaleza no se limita solo a la selva, sino se extiende al mar y al clima también. Dentro de La perra, estos tres aspectos trabajan en conjunto para proyectar un espacio indomable que se resiste -a veces literalmente con uñas y dientes- al proyecto capitalista y neocolonizador. De nuevo, Quintana va a recodificar la idea modernizadora de que "la 'jungla', como la manigua y la selva...articulan nociones de desarrollo y control de los recursos naturales" (Rodríguez, p. 33). Quintana no ve a la naturaleza con los mismos ojos y rearticula esa noción occidental de la explotación de la tierra. Quintana escribe que "la cabaña donde vivían [Damaris y Rogelio]...temblaba con los truenos y se hamacaba con el viento, el agua se metía por las goteras del techo y las rendijas entre las tablas

2 Henry David Thoreau (1817-1862), conocido como una de las figuras más representativas del movimiento norteamericano del Trascendentalismo, escribe Walden (1854) como ensayo a favor de la idea de vivir conscientemente y lejos del materialismo de las ciudades. Es una reflexión sobre su tiempo viviendo apartado de la sociedad en una choza en medio del bosque al lado del estanque de Walden en el estado de Massachusetts, EEUU. Entre otros argumentos, se destacan la soledad y la simplicidad -o una vida ascética - como maneras de liberarse de la cadenas que ataban al ser humano a una vida miserable y destinada al consumismo. 
de las paredes, todo se enfriaba y humedecía" (p. 16). En estas circunstancias, se hace evidente aún más el poder de la naturaleza. Es decir, que no es el hombre que somete a la naturaleza sino la naturaleza que somete al hombre. Es más, el poder climático llega a tal punto que no hay estructura que resista su fuerza; la civilización se muestra siempre frágil y vulnerable frente al entorno selvático.

Además, y tal como se espera, la fragilidad de lo humano no queda reducida al mundo físico sino, como se veía antes, encuentra la manera de meterse en los sueños y anclarse en el imaginario de los sujetos. Quintana ilustra esta intrusión climática y cómo deviene en una intrusión metafísica, arrebatando control de los sueños de Damaris con imágenes de terror que -de una manera que anticipa el final de la novela- la transforma en parte del paisaje que la rodea. Narra Quintana:

Soñaba [Damaris] con ruidos y sombras, que estaba despierta en su cama, que no podía moverse, que algo la atacaba, que era la selva que se había metido en la cabaña y la estaba envolviendo, que la cubría de lama y le llenaba los oídos con el ruido insoportable de los bichos hasta que ella se convertía en selva, en tronco, en musgo, en barro, todo al mismo tiempo...Cuando se despertó seguía sola. Afuera caía una tormenta brutal, con vientos de los que azotaban las tejas y truenos que hacían temblar la tierra; el agua se colaba por las rendijas y flotaba dentro de la cabaña. (p. 51)

Así, la tormenta que sucede afuera invade su pieza y la viola, convirtiéndola en parte de la misma selva a la que da vida la tempestad.

En cambio, se atestigua al poder del mar en el día a día de Damaris, donde como parte de su rutina ella tiene que cruzar una caleta pérfida para llegar al pueblo y hacer las compras. Sin embargo, este cruce implica un proceso arriesgado ya que en todo momento está a la merced de una marea que "subía rápida, oscura y silenciosa como una anaconda colosal" (Quintana, p. 74). Quintana va más a fondo para revelar lo traicionero que es, describiendo al mar como "tranquilo como una piscina infinita", para luego aclarar que "Damaris no se dejó engañar. Ella sabía muy bien que ese era el mismo animal malévolo que tragaba y escupía gente" (p. 99). Tal como se había visto antes cuando Quintana refería a la selva como una bestia, en esta oportunidad también se experimenta una instancia de animalización del mar que hace presa y ataca a los más vulnerables. Así, encima de los peligros conocidos de una marea previsible y rutinaria, aquí el mar es 
insidioso, destacándose más por ser disimulado, capaz de secuestrar y devolver sin vida a los que se distraen por un solo instante tal como se verá más adelante.

Está en las manos del mar que mueren sin piedad tres figuras durante la novela. De todas maneras, la figura en la que se pondrá el foco es Nicolasito, el hijo de una familia rica apellidada los Reyes, que vivía en Bogotá e iba de vacaciones a la costa. En primer lugar, al enterarse de qué clase proviene Nicolasito, da que pensar en lo que afirma Scott DeVries de que históricamente la selva representaba "a place of refuge for civilized individuals from the maddening crowd of overindustrialized cities" (p. 539). De acuerdo con esta opinión, los Reyes usan la naturaleza como escape de la civilización. Aún más, es factible entender su relación con la naturaleza de una manera más siniestra. Al tomar sus vacaciones y construir su pequeño castillo innovador allá, ellos abusan de la naturaleza y de la gente de la región mediante la mano de obra barata. Ellos alteran física e irremediablemente al paisaje para poder en este caso, "construir una casa grande, toda de láminas de aluminio - el material más moderno que existía en ese momento-, con piscina y un quiosco amplio con lavaplatos y fogón de leña para los sancochos, los asados y las fiestas" (Quintana, p. 29). Los Reyes encarnan esa misión civilizadora y la explotación que pregonaba Sarmiento.

En este contexto se entiende la naturaleza como un espacio utópico, que la gente de la ciudad puede "habitar" desde detrás de las ventanas de su casa sin considerar los daños colaterales al medioambiente. Es decir, sin la necesidad de ensuciarse las manos y entrar en contacto con lo que queda al otro lado de sus ventanas, los Reyes colocan a la naturaleza en una posición de marginalidad. No hay ningún compromiso espiritual o afectivo con la naturaleza; simplemente representa el "otro" espacio y el espacio de otredad. De esta manera se cosifica la naturaleza y se convierte en algo que se aprecia a lo lejos y que existe por el uso exclusivo del ser humano. En este caso la naturaleza es en un simple objeto nacido de lo que Ileana Rodríguez explica como "un impulso obstinado con la transformación del paisaje" (p. 31). Aquí, los foráneos irrumpen en la escena, revelando una de las formas en las cuales la clase capitalista explota y subyuga un entorno sin pensar en el orden natural de la región.

Es a esta intrusión neocolonizadora y capitalista a la que la naturaleza responde cuando da muerte a Nicolasito y su visión romantizada de la selva. Es Nicolasito quien, frente al aviso de Damaris, quien conocía las particularidades del terreno y los peligros del mar, "no hizo caso, se paró sobre las peñas y la ola que reventó en ese momento, una ola violenta, se lo llevó" (Quintana, p. 30). Nicolasito estuvo desaparecido durante treinta y cuatro días antes de que volviera a aparecer en las 
playas, "despellejado por la acción del salitre y el sol, comido por los peces en algunas partes hasta el hueso, y según dijo la gente que estuvo cerca, hediondo" (Quintana, p. 32). La muerte de Nicolasito ratifica el poder y la falta de piedad de la naturaleza. Al mismo tiempo socava la dicotomía perniciosa de Sarmiento como el mar al cadáver de niño, y la invierte en contra de las incursiones neocolonizadoras que buscan sacar provecho del mundo natural y expandir sus mercados en nombre del progreso.

No obstante, Nicolasito no es el único de la familia de los Reyes que sufre los efectos de la naturaleza; trae con sí misma efectos secundarios también. Después de su muerte y con el correr del tiempo, hasta la casa grande de la familia, armada con materiales resistentes, "necesitaba una mano de pintura y que reemplazaran un par de lámina agrietadas...[y] el pavimento se había podrido en algunos tramos" (Quintana, p. 39). El deterioro de la casa pone aún más en evidencia la fragilidad de lo humano ante los elementos de la naturaleza. Esta vulnerabilidad de la casa volverá a aparecer al final de la novela en un acontecimiento simbólico que reafirma la inversión de la relación entre la civilización y la barbarie y el rechazo de lo civilizado: la destrucción de las cortinas con imágenes de El libro de la selva $a^{3}$ que decoraban el cuarto de Nicolasito por la perra.

Antes de profundizar este acaecimiento, es menester subrayar algunos aspectos de la familia de los Reyes dentro de la sociedad colombiana de la novela. Como familia pudiente de Bogotá cuya figura paternal es dueño de una fábrica de maletines, los Reyes sobresalen como sinécdoque por esa clase emprendedora que busca nuevos horizontes tanto para expandir su empresa como para el ocio. En otras palabras, ellos se lucran a costa de los otros para su propio beneficio. Por eso, casi al final de la novela cuando Damaris se encuentra limpiando la casa abandonada de los Reyes y reflexionando sobre su respuesta a Nicolasito sobre

3 Se debe repasar algunos detalles de El libro de la selva (1894) escrito por Rudyard Kipling (1865-1930), escritor inglés nacido en Bombay cuya inspiración se basaba en la naturaleza de ese país. Kipling nació en la ciudad y comprendía la selva como un refugio de ella; un escape idealizado donde uno podía encontrar la paz observando todo a lo lejos. Esta obra en particular manifiesta una visión romántica de la selva en la cual es mirada como aliado maternal del ser humano que rescata y acobija al hombre afligido. Si bien existen peligros en ella, el ser humano civilizado puede sobrevivir - y aún más prosperar - dentro de ella mediante la interdependencia. En cierto sentido uno puede leer estos cuentos de Kipling con un ojo ecocrítico ya que en un principio la relación del hombre con la naturaleza es una de respeto mutuo. No obstante, también se los puede entender como una intrusión e imposición de la civilización sobre la naturaleza, cuya presencia cambia irrevocablemente el orden natural de la selva. En los cuentos, el mayor obstáculo a esta presencia se encarna en el tigre Shere Khan que al final muere a las manos de Mowgli (ser humano y el protagonista), quien después de despellejar al cadáver del tigre termina bailando sobre la piel en un acto que da a entender la conquista del hombre y su dominio absoluto posterior a esta victoria. 
El libro de la selva y esa historia que "se trataba de un niño que se perdía en la selva y lo salvaban los animales" (Quintana, p. 97), se deja traslucir una connotación importante dentro de la novela.

Esta fascinación de Nicolasito con El libro de la selva y la destrucción de las cortinas que adornan su habitación marcan un momento bisagra en la novela en la relación entre naturaleza y ser humano, o barbarie y civilización. Todo pasa al final cuando Damaris llega a la casa abandonada de los Reyes para hacer la limpieza y encuentra que "las cortinas del finado Nicolasito estaban en el suelo, sucias de barro y desgarradas...Estaban destrozadas hasta el punto de que sería imposible repararlas" (Quintana, p. 100). En destrozar estos decoros grabados con imágenes de El libro de la selva -libro escrito por un hombre de la ciudad, que representa la superioridad de la civilización, y cuyo "dueño" era una familia citadina- la naturaleza desromantiza el mito de que los seres humanos pueden dom(in)ar a la naturaleza. Esta acción llevada a cabo por la perra ilustra que son -y serán siempre - el poder de la naturaleza y el reino animal los que subordinan al ser humano y no el revés.

Sin embargo, no es solo que Chirli destruya las cortinas, sino la reacción de Damaris después de verlas y quedar horrorizada con lo sucedido lo que ilustra la influencia de la naturaleza en ella porque es aquí donde sale a la luz la furia incontenible que la naturaleza ha inculcado en Damaris. Es en su reacción donde se manifiesta que todo discurso dominante asimilado por Damaris durante su vida queda en el olvido frente al de la naturaleza. Quintana escribe:

Damaris agarró una soga para amarrar lanchas, le hizo un nudo corredizo, salió del quiosco por el lado que daba hacia la piscina, lo rodeó, entró por el paso del fogón y enlazó a la perra por detrás, antes de que ella pudiera darse cuenta de lo que le estaba pasando. Jaló la soga para que el nudo se apretara, pero en vez de detenerse, sacarle la soga del cuello y cruzársela, siguió apretando y apretando, luchando con toda su fuerza mientras la perra se retorcía ante sus ojos, que parecían no registrar lo que veían, que lo único que registraron fueron las tetas hinchadas del animal.

"Está preñada otra vez", se dijo y siguió apretando con más ganas, apretando y apretando, hasta mucho después de que la perra cayó extenuada, se hizo un ovillo en el suelo y dejó de 
moverse. (p. 100-101)

Damaris, en fin, mata salvajemente a Chirli y los cachorros que llevaba adentro sin el menor rastro de compasión, como si fuera ese "animal malévolo que tragaba y escupía gente" (p. 99), que Quintana elucidaba antes; al mismo tiempo, responde al miedo detrás de la cita de Sarmiento que abre este estudio: "De eso se trata: de ser o no ser salvaje" (p. 11). Damaris, efectivamente, es salvaje y actúa como tal. Ella reacciona sin razonamiento alguno. Poco le importa que haya matado a su perra y poco le importa que haya matado a los cachorros que aún no habían nacido. Se le desbordan los instintos primitivos que la naturaleza (y la cultura nacida de esa naturaleza y sostenida por la sociedad) le infundía a lo largo de los años. Pero no solo le pasa a ella; este acto hasta se asemeja mucho a un episodio violento anterior de su esposo Rogelio cuando, frente a su perro que tenía una herida infectada en la cola, en vez de llevarlo al pueblo a un veterinario, "lo agarró por la punta de la cola, alzó su machete y...se la cortó de tajo" (Quintana, p. 13). Tanto Damaris como Rogelio no piensan ni tienen en cuenta las consecuencias; solo actúan. De la misma manera que Rogelio, Damaris tampoco siente remordimiento, y como carnívora después de matar a su presa, "observó todo con horror, pero también con una especie de satisfacción que era mejor no reconocer y enterrar detrás de las otras emociones" (p. 101). Tiene una reacción enfrentada que vacila entre culpa y deleite, entre civilización y barbarie. No obstante, la naturaleza le puede y tal como la mujer de que había escuchado hablar y que había despedazado a su esposo en un pueblo cercano, Damaris tiene "la mirada de una asesina...la mirada de alguien que no se arrepiente y siente alivio de haberse librado de una carga" (Quintana, p. 104).

Esto es el salvajismo que se hacía evidente en Facundo y al que Sarmiento quería poner fin antes de que se pudiera propagar en las ciudades como si fuera la invasión cotidiana de hormigas que arrasaba con todo a la que Quintana se hizo referencia anteriormente. Si bien la idea de Sarmiento era aniquilar la barbarie para poder explotar los recursos naturales, el verdadero motivo era acabar con la tiranía y la ignorancia de la barbarie, reemplazándolas con ideas y prácticas liberales que enaltecían el poder del "yo" frente al mundo. Uno de los mayores miedos de Sarmiento paraba en una sociedad reaccionaria que actuaba primero sin deliberar las consecuencias; es decir, una sociedad falta de conocimiento y raciocinio. No obstante, dentro de Damaris los instintos y la crudeza de la naturaleza, o como argumenta Sarmiento cuando se refiere a la barbarie, "la ignorancia de este poder brutal” (p. 20), resuenan con más fuerza, desvelando una y otra 
vez el dominio que mantienen sobre ella y sobre los demás pueblerinos de este ambiente inhóspito lejos de la civilización.

Es al final de la novela, sin embargo, cuando los lectores se enfrentan con la verdadera influencia de la selva y lo arraigada que está en Damaris. Después de matar a Chirli, Damaris lleva al cadáver de la perra a un lugar en la selva donde nadie pasaba y "bastarían tres o a lo sumo cuatro días para que...quedara reducido a los huesos" (Quintana, p. 105). No obstante, la reacción de Damaris después de abandonar el cuerpo en la selva llama mucho la atención. En el cierre se encuentra a una Damaris que "se siente perdida" (Quintana, p. 108), no solo por el acto que acaba de realizar, sino perdida por una serie de acontecimientos y normas a lo largo de su vida que ha culminado en este instante. Ella está desorientada; naufraga entre los discursos de poder que ha seguido ciegamente toda su vida y este discurso de la naturaleza que ha sido latente dentro de ella, ganando fuerza y acumulando poder hasta este mismo momento. La muerte de su amigo Nicolasito, la desaparición y luego muerte de su madre, una relación sin amor, una maternidad frustrada y ahora el abandono y luego asesinato de la perra a sangre fría son solo algunos de los sucesos que han acarreado serias dificultades a Damaris. Por eso ella decide que

tal vez debería irse al monte, descalza y apenas en su licra corta y su blusa de tiras desteñida, y caminar más allá de La Despensa, la estación de cultivo de peces, los terrenos de la Armada, los lugares que había recorrido con Rogelio y los que no habían llegado a conocer, para perderse como la perra y el niño de las cortinas de Nicolasito, allá donde la selva era más terrible. (Quintana, p. 108)

Es a partir de este momento que deja abierto el final. El que se discutirá aquí se inclina al argumento principal de esta investigación: que la selva se asocia íntimamente con la mortalidad. A lo largo de la narrativa, la selva ha sido presentada como un lugar marcado por la violencia y el salvajismo, un ente opresivo que opera sin piedad sobre -y dentro de- los que la habitan. Este concepto de la selva es el que la cultura le inculcaba a Damaris cuando era niña y el que sigue tan enquistado en el imaginario de ella. Esta es la visión que se ha convertido en naturaleza dentro de Damaris y por eso ella reconoce que en esta visión radica su única salida del mundo: la muerte. Ella entiende que el único escape que le queda a esta vida llena de fracasos y regida por esencialismos inescapables que la llevan a sentirse "derrotada e inútil, una vergüenza como mujer, una piltrafa de 
naturaleza" (Quintana, p. 24) por no poder cumplir con las expectativas sociales, es hacerse desaparecer dejándose sucumbir ante las fuerzas naturales.

La perra se presta para ser interrogada de muchas maneras. Por ahora, más allá de analizarla de una manera que siga con cualquiera de las tendencias "eco" en el ámbito de la crítica literaria, en el presente trabajo solo se ha propuesto meditar el papel de la naturaleza y el medioambiente dentro de esta representación de novela de la selva contemporánea. Aquí se ha mostrado la contracara de la relación maniquea que formuló Sarmiento en el siglo XIX entre la civilización y la barbarie, argumentando que por más que los pensadores liberales del siglo XIX lo haya intentado frenar, la naturaleza siempre supo imponerse en los seres humanos. El poderío que demuestra la naturaleza una y otra vez en La perra, más su influencia en los personajes deja entrever que la dicotomía en la que la civilización superaba y subordinaba a la barbarie no da para más. En cuanto a la novela en sí, si bien todas las interacciones humanas de Damaris la han llevado a dejarse convencer por la idea de que se sentía una piltrafa, como se ha observado, más que estas interacciones son la selva y las fuerzas naturales las que terminan por llevarla a contemplar su propia muerte perdida en medio de la selva. Es la naturaleza la que forma a Damaris y la que se enquista en ella. Para Damaris, estar junto a la naturaleza, dejarse rendir ante su poder, muerta en ella, su cadáver carcomido sin piedad dentro de sus entrañas, significa la libertad y la única manera de separarse definitivamente de una cultura patriarcal y una sociedad que la asfixian, dándole de comer con su propio cuerpo para luego fundirse en ella.

\section{Referencias Bibliográficas}

Barbas-Rhoden, L. (2012). Ecological Imaginations in Latin American Fiction. Gainesveille: University Press of Florida.

DeVries, S. (2010). Swallowed: Political Ideology and Environmentalism in the Spanish American "Novela de la Selva". Hispania, 93(4), 535-546.

Kearns, S. (2006). Nueva conciencia ecológica en algunos textos femeninos contemporáneos. Latin American Literary Review, 34(67), 111-127.

Mannes, C (1996). Nature and Silence. En C. Glotfelty \& H. Fromm (Eds.). The Ecocriticism Reader: Landmarks in Literary Ecology (15-29). Athens, Georgia: University of Georgia Press.

Mutis, A. (2014). Del río a la cloaca: La corriente de la conciencia ecológica en la literatura colombiana. Revista de Crítica Literaria Latinoamericana, 40(79), 181-200. 
Ospina, M. (2014). Las naturalezas de la guerra: Topografías violentas de la selva en la narrativa contemporánea colombiana. Revista de Crítica Literaria Latinoamericana, 40(79), 243-264.

Plumwood, V. (2006). The Concept of a Cultural Landscape: Nature, Culture, and Agency in the Land. Ethics and the Environment, 11(2), Special Topics Issue Nature/Culture Dualism, 115-150.

Quintana, P. (2017). La perra. Bogotá: Literatura Random House.

Rodríguez, I. (1997). Naturaleza/nación: Lo salvaje/civil Escribiendo Amazonia. Revista de Crítica Literaria Latinoamericana, 23(45), 27-42.

Rogers, C. (2016). Mario Vargas Llosa and the novela de la selva. Bulletin of Spanish Studies, 93(6), 1043-1060.

Sarmiento, D.F. (2001). Facundo. Buenos Aires: Gradifco.

Wylie, Lesley (2006). Colonial Tropes and Postcolonial Tricks: Rewriting the Tropics in the "Novela de la Selva". The Modern Language Review, 101(3), 728-742. 
